\title{
Interação de variáveis biomecânicas na composição de "feedback" visual aumentado para o ensino do ciclismo
}

CDD. 20.ed. 796.023

796.6

\author{
Guilherme Garcia HOLDERBAUM* \\ Ricardo Demétrio de Souza PETERSEN* \\ Antônio Carlos Stringhini GUIMARÃES (in memoriam)* \\ *Escola de Educação \\ Física, Universidade \\ Federal do Rio Grande \\ do Sul.
}

\section{Resumo}

0 objetivo deste estudo foi testar uma metodologia para o ensino da técnica da pedalada do ciclismo utilizando variáveis biomecânicas para desenvolver um sistema de "feedback" visual aumentado (FVA). Participaram do estudo 19 indivíduos, sem experiência no ciclismo, divididos em grupo experimental (n $=10$ ) e controle $(n=9)$. Inicialmente foi realizado um pré-teste para determinar o consumo máximo de oxigênio $\left(\mathrm{VO}_{2 \text { max }}\right)$ bem como a carga de trabalho utilizada nas sessões práticas que correspondeu a $60 \%$ do $\mathrm{VO}_{2 \text { máx }}$ Em seguida foram realizadas sete sessões de prática. 0 grupo experimental foi submetido ao FVA e o grupo controle ao "feedback" aumentado (FA). 0 teste de retenção mostrou um aumento de $21 \%$ na média do índice de efetividade (IE) do grupo experimental quando comparado ao grupo controle. Os resultados mostraram que variáveis biomecânicas são apropriadas para o desenvolvimento de FVA e podem contribuir no processo de ensino-aprendizagem da técnica da pedalada do ciclismo.

UnIteRMos: Ciclismo; Técnica da pedalada; Variáveis biomecânicas; Aprendizagem motora; "Feedback" visual aumentado.

\section{Introdução}

O ciclismo tem se tornado um esporte muito estudado nos últimos anos, especialmente nas áreas da biomecânica e da fisiologia do exercício. Recentemente pode-se perceber um aumento nos estudos com ênfase na caracterização da técnica da pedalada, mais especificamente, na forma como os ciclistas aplicam e direcionam as forças no pedal da bicicleta (BRoKer, Gregor \& SCHMidT, 1993). Isto deve-se, provavelmente, ao fato de que o ciclismo está se tornando um esporte cada vez mais competitivo, sendo as provas decididas em frações de segundos. Este fato demonstra que esta modalidade é altamente técnica e necessita de estudos aprofundados em relação a sua técnica, para que a mesma possa ser ensinada (Holderbaum, Guimaráes \& Petersen, 2009) e, dessa forma, melhorar a performance no esporte.

No entanto, poucos são os estudos relacionados com o ensino da técnica da pedalada encontrados na literatura. Esta lacuna pode ser decorrente da dificuldade de se desenvolver estratégias que possam auxiliar no processo de ensino-aprendizagem deste esporte. Talvez, com a utilização de variáveis biomecânicas, aliadas a conceitos da aprendizagem motora, seja possível controlar e, até mesmo, ensinar a técnica da pedalada.

Uma estratégia que pode influenciar o processo de ensino-aprendizagem de um gesto técnico é a utilização de "feedbacks" (SANDERson \& CavanaGH, 1990). "Feedbacks" consistem de informações que surgem como resultado do movimento e são repassadas ao aprendiz (GoDoy, 1994).

Dentre os tipos de "feedback", está o visual aumentado (FVA), que consiste de informações transmitidas de forma visual ao aprendiz no final do movimento, complementando a informação verbal transmitida pelo professor (BROKER, GREGOR \& SCHMIDT, 1993; Holderbaum, Guimarāes \& Petersen, 2009; SanDERSON \& CAVANAGH, 1990). Entretanto, esta informação visual deve representar um componente ou variável fundamental para a realização do movimento (SANDERSON \& CAVANAGH, 1990), pois o objetivo do FVA é permitir ao aprendiz verificar a diferença 
entre o seu padrão de movimento e a referência a ser alcançada para que, por meio da imagem e das informaçōes fornecidas, ele consiga, mais facilmente, alcançar a técnica almejada de movimento.

$\mathrm{Na}$ literatura, o sistema de "feedback" visual aumentado vem sendo utilizado como uma ferramenta determinante no processo de ensino-aprendizagem da técnica da pedalada no ciclismo (BROKER, GREGOR \& SCHMidt, 1993; HenKe, 1998; SANDERSON \& CAVANAGH, 1990). Nestes estudos, variáveis biomecânicas, que comumente caracterizam a técnica da pedalada no ciclismo, como a força no pedal e o índice de efetividade, são utilizadas como referência a ser alcançada no FVA. Estas variáveis são medidas a partir de uma plataforma de força adaptada em um pedal de ciclismo. Este instrumento é chamado de pedal instrumentado e permite o conhecimento das componentes de força nele aplicadas (Álvarez \& VinYolas, 1996).

A componente tangencial da força $(\mathrm{Fx})$ atua paralelamente à superfície do pedal, enquanto que a componente normal da força $(\mathrm{Fy})$ atua perpendicularmente à superfície do pedal. A partir destas duas componentes da força é possível calcular a força efetiva (FE), esta aplicada perpendicularmente ao pé-de-vela e considerada como a força geradora de propulsão da bicicleta (BROOKE, Hoare, Rosenrot \& Triggs, 1981; Candotti, 2003; Davis \& Hull, 1981; Hull \& DaVis, 1981; Hull \& Wootten, 1996; Sanderson \& CaVanagh, 1990).

As componentes de força aplicadas ao pedal apresentam comportamentos diferenciados ao longo do ciclo da pedalada. Entende-se por ciclo da pedalada a circunferência descrita pelo pedal da bicicleta quando o mesmo parte do ponto mais alto deste ciclo (considerado como $0^{\circ}$ graus) e realiza um movimento de giro até retornar a mesma posição (considerada, então como $360^{\circ}$ ).

\section{Método}

Dezenove alunos $(\mathrm{n}=19)$ de uma escola pública localizada no município de Montenegro/RS participaram deste estudo. Ambos do sexo masculino, entre 14 e 16 anos de idade, sem experiência em competições de ciclismo e nunca utilizaram pedaleiras em suas bicicletas. Estes indivíduos foram divididos em dois grupos: experimental $(\mathrm{n}=10)$ e controle $(\mathrm{n}=9)$.

Os indivíduos e seus responsáveis foram informados dos objetivos e procedimentos envolvidos no estudo. Um termo de consentimento informado foi elaborado e assinado pelos pais
Pode-se analisar o ciclo de pedalada dividindo-o em duas fases: a fase de propulsão (de $0^{\circ}$ a $180^{\circ}$ ) e fase de recuperação (de $180^{\circ}$ a $360^{\circ}$ ), ou em quatro quadrantes: o $1^{\circ} \mathrm{de} 0^{\circ}$ a $90^{\circ}$, o $2^{\circ}$ de $90^{\circ}$ a $180^{\circ}$, o $3^{\circ}$ de $180^{\circ}$ a $270^{\circ}$, e o $4^{\circ}$ de 270 a $360^{\circ}$ (LAFORTUNE $\&$ CAVANAGH, 1983). As variáveis magnitude, direção e sentido de aplicação de força no pedal possuem combinações diferenciadas nas duas fases e nos quatro quadrantes do ciclo da pedalada implicando diretamente na propulsão gerada.

Acredita-se que, com a interação destas variáveis biomecânicas, como as forças presentes no movimento da pedalada bem como o conhecimento acerca do ciclo da pedalada, seja possível compor um sistema de FVA para auxiliar no processo de ensino-aprendizagem do ciclismo. No entanto, embora o FVA seja um dos mais importantes fatores que controlam a performance e o aprendizado, parece ser discutível a sua utilização, uma vez que a integralidade da informação visual pode causar dependência ao aprendiz, comprometendo a realização do movimento quando este FVA for removido (SANDERSON \& CAVANAGH, 1990; SCHMIDT \& WRISBERG, 2001). Assim, entende-se necessário o desenvolvimento de estudos que venham elucidar as questôes acerca da aprendizagem do ciclismo com a utilização do FVA para a melhoria da técnica da pedalada.

Então, na tentativa de contribuir com estudos já realizados anteriormente e referenciados na literatura, este trabalho buscou reunir diferentes variáveis biomecânicas, bem como conhecimentos da aprendizagem motora para desenvolver e aplicar um sistema de "feedback" visual aumentado que possibilite o ensino da técnica da pedalada do ciclismo e mantenha o nível de aprendizado mesmo quando este FVA for removido.

ou responsáveis pelos indivíduos após não haver mais quaisquer dúvidas sobre o estudo bem como sobre a possibilidade de encerrar a participação no mesmo a qualquer momento. Os indivíduos passaram por um processo de familiarização com as avaliaçôes realizadas, bem como com os protocolos e equipamentos. Este estudo foi aprovado pela comissão de pesquisa da Escola de Educação Física da Universidade Federal do Rio Grande do Sul, pela Administração da Escola (Direção, Supervisão Escolar e Conselho Escolar) bem como pela 2a Coordenadoria Regional de Educação. 


\section{Período pré-experimento}

O período de pré-experimento foi dividido em dois dias de avaliações. No primeiro dia de avaliação, os indivíduos foram submetidos ao protocolo de rampa para determinação do consumo máximo de oxigênio $\left(\mathrm{VO}_{2 \text { max }}\right)$. Para este teste foi utilizado um cicloergômetro computadorizado ERGOFIT (Medical Graphics Corp., St. Louis, USA) que fornece a carga de trabalho de cada estágio e cadência, e um ergoespirômetro CPX/D (Medical Graphics Corp., St Louis, USA) que permite a medida direta do $\mathrm{VO}_{2}$.

No segundo dia de avaliação, os indivíduos foram submetidos ao protocolo de identificação dos valores da carga de trabalho e frequência cardíaca a serem utilizadas nas sessōes de prática o que correspondeu a $60 \%$ do $\mathrm{VO}_{2 \max }$ de cada indivíduo, bem como aos registros dos sinais de dinamometria (forças) e eletrogoniometria (ângulos do pedal relativo ao movimento do pé-de-vela e do pé-de-vela). Para tanto foi utilizado o mesmo ergoespirômetro, já descrito anteriomente e um cicloergômetro da marca Monark (modelo GIH - Stockholm, Sweden) com ajuste manual de carga. Para o registro das forças, utilizou-se um pedal-plataforma de força acoplado ao cicloergômetro e diretamente conectado a um condicionador de sinais Entran MSC6 (Entran Itd., England) com módulos MSC-A1 utilizando alimentação de ponte de $1 \mathrm{~V}$ e ganho de $1 \mathrm{~K}$. O sistema fornece informações sobre as componentes da força normal e tangencial. $\mathrm{O}$ condicionador de sinais foi conectado a um microcomputador Pentium II $200 \mathrm{HZ}$ e a um conversor analógico-digital de 16 canais CODAS (Dataq Instruments, Inc., Akron, USA). Os procedimentos de calibração do pedal-plataforma adotados neste estudo estão de acordo com outros estudos referenciados na literatura (Dreyer Neto, Schmidt, Candotti, Loss, Zaro, Cervieri \& Guimarāes, 2001).

Para o registro do ângulo do pedal relativo ao movimento do pé-de-vela utilizou-se um potenciômetro do tipo Spectrol $2 \mathrm{k} \Omega$, acoplado ao pedal-plataforma. $\mathrm{O}$ ângulo do pé-de-vela foi mensurado com o uso de um sensor eletromagnético do tipo "reed switch", como já utilizado (HuG, DeCherChi, Marqueste \& Jammes, 2003; Welbergen \& ClIJSEN, 1990). Este consiste de um ímã fixado no início do ciclo da pedalada (zero graus do pé-de-vela) e outro fixado no pé-de-vela do cicloergômetro na mesma altura. Dessa forma, tem-se o início e o final do ciclo de pedalada (de 0 a 360 $)$, possibilitando assim, o cálculo do ângulo do pé-de-vela.

A cadência de $60 \mathrm{rpm}$ foi adotada tanto para o segundo dia de avaliação do período de préexperimento quanto para as sessões de prática por se tratar de uma frequência de giro mais lenta, o que favorece a aprendizagem motora do gesto técnico do ciclismo (Magill, 2000). Para o controle da cadência de pedalada foi utilizado um ciclo computador da marca ECHO-F2 .

A carga correspondente a $60 \% \mathrm{doVO}_{2 \max }$ foi adotada por se tratar de um nível de intensidade moderada de exercício o que equivale a um treinamento para melhoria da capacidade aeróbica (McARdLE, KaTCH \& КАTCH, 1992) e para estabelecer um critério de normalização fisiológica da carga de trabalho para os indivíduos (Holderbaum, Guimarāes \& Petersen, 2009).

A duração deste teste dependeu do tempo de estabilização do $\mathrm{VO}_{2}$. Após a estabilização do $\mathrm{VO}_{2}$, foi realizado o registro das forças aplicadas ao pedal, assim como dos ângulos do pedal relativo ao pé-devela e do ângulo do pé-de-vela durante um minuto. A frequência de amostragem foi de $2300 \mathrm{~Hz}$ para cada canal dos sinais de dinamometria e eletrogoniometria.

As sessões de prática tiveram início 48 horas após o término das avaliações do pré-experimento.

\section{Sessões de prática}

Para a aquisição dos sinais de dinamometria durante as sessōes de prática foi utilizado o "software" Sistema de Aquisição de Dados SAD32 (versão 2.61.07mp, 2002; Laboratório de Medições Mecânicas da Escola de Engenharia da Universidade Federal do Rio Grande do Sul - www.ufrgs.com.br/lmm). Para a realização das sessões de prática foram utilizados os mesmos cicloergômetro, pedal plataforma de força e condicionador de sinais já descritos anteriormente no período de pré-experimento. O condicionador de sinais foi conectado a um microcomputador Celeron $1000 \mathrm{HZ}$ equipado com uma placa A/D (analógicodigital) de 16 canais CIO-DAS 16 / Jr / 330 /1600 $\mathrm{Hz}$ (Dataq Instruments, Inc., Akron, USA). 
A elipse indica o pedalplataforma de força.

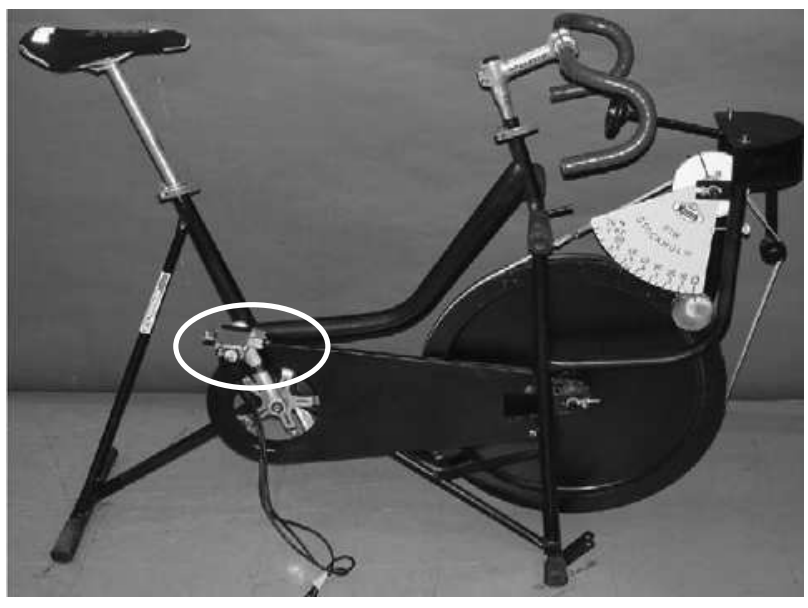

FIGURA 1 - Cicloergômetro da marca Monark (modelo GIH - Stockholm, Sweden) com ajuste manual de carga.

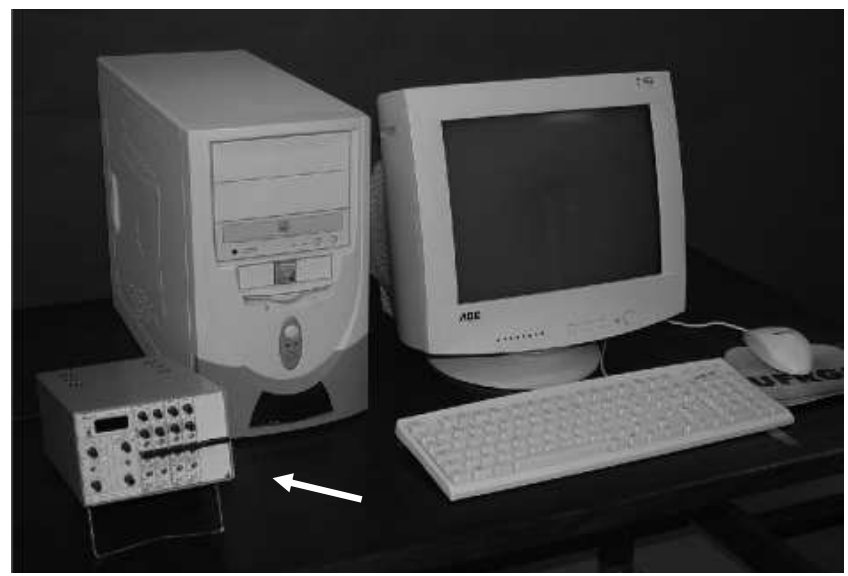

FIGURA 2 -A seta indica o Condicionador de sinais conectado ao computador Celeron $1000 \mathrm{~Hz}$ equipado com a placa A/D CIO-DAS.

Durante as sessões, foi solicitado aos indivíduos que adotassem a cadência de $60 \mathrm{rpm}$. Para o controle da cadência de pedalada foi utilizado um ciclo computador modelo ECHO-12.

A carga correspondente a $60 \%$ do $\mathrm{VO}_{2 \max }$ de cada indivíduo foi mantida ao longo de todas as sessões de prática. Dessa forma, os indivíduos estiveram sempre no mesmo nível de esforço, ou seja, pedalando a $60 \%$ do seu próprio $\mathrm{VO}_{2 \operatorname{máx}}$ identificado no período de préexperimento. Adotou-se este procedimento a fim de normalizar fisiologicamente, para todos os indivíduos, a carga de trabalho.

Todos os indivíduos, de ambos os grupos, controle e experimental, antes de serem submetidos às sessões de prática, passaram por um processo de familiarização com os equipamentos e procedimentos utilizados neste estudo, bem como receberam as mesmas instruçôes: 1) manter a cadência durante as sessões de prática da técnica da pedalada; 2) aumentar o padrão de aplicação de força efetiva na fase de propulsão; 3) diminuir a presença de forças retrógradas na fase de recuperação; e 4) melhorar o índice e a taxa de efetividade ao longo do ciclo da pedalada.

A diferença entre as sessões de prática para os dois grupos estava na presença do FVA para o grupo experimental e do FA para o grupo controle. O FVA para o grupo experimental caracterizou-se pelo fornecimento de instruçōes verbais do avaliador juntamente com as explicações da planilha de orientação sobre o direcionamento das forças normal e tangencial em cada quadrante do ciclo da pedalada. Além disso, este grupo recebeu, também, a imagem visual representativa da curva de FE produzida pelo indivíduo que estava pedalando, sobreposta a uma curva de FE produzida por um ciclista de elite. Estas curvas eram apresentadas ao indivíduo na tela do computador. Assim, era possível mostrar, ao indivíduo, o quão distante ou próximo, estava a sua técnica em relação à técnica de um ciclista de elite. 
O grupo controle recebeu as mesmas instruções verbais do avaliador juntamente com as mesmas explicaçôes da planilha de orientação sobre o direcionamento das forças normal e tangencial em cada quadrante do ciclo da pedalada, o que caracteriza o FA para este grupo. Entretanto, o grupo controle não recebeu a informação visual da sua curva de FE sobreposta à curva de FE do ciclista de elite.

As informaçôes verbais fornecidas aos indivíduos de ambos os grupos estavam relacionadas ao direcionamento das forças aplicadas ao pedal, e foram transmitidas aos indivíduos de forma idêntica nos intervalos da série de prática da seguinte forma:

"1o quadrante: Empurra o pedal para baixo e empurra o pedal para frente"; "2o quadrante: Empurra o pedal para baixo e puxa o pedal para trás";

"3o quadrante: Puxa o pedal para cima e puxa o pedal para trás";

"4o quadrante: Puxa o pedal para cima e empurra o pedal para frente".

Estas mesmas informações verbais também foram transmitidas de forma visual para ambos os grupos através de uma planilha de orientação sobre o direcionamento das forças aplicadas ao pedal em cada quadrante do ciclo da pedalada (FIGURA 3). Esta planilha permitiu ao avaliador explicar, de forma clara, para onde o indivíduo deveria direcionar suas forças normal e tangencial ao longo dos quatro quadrantes.

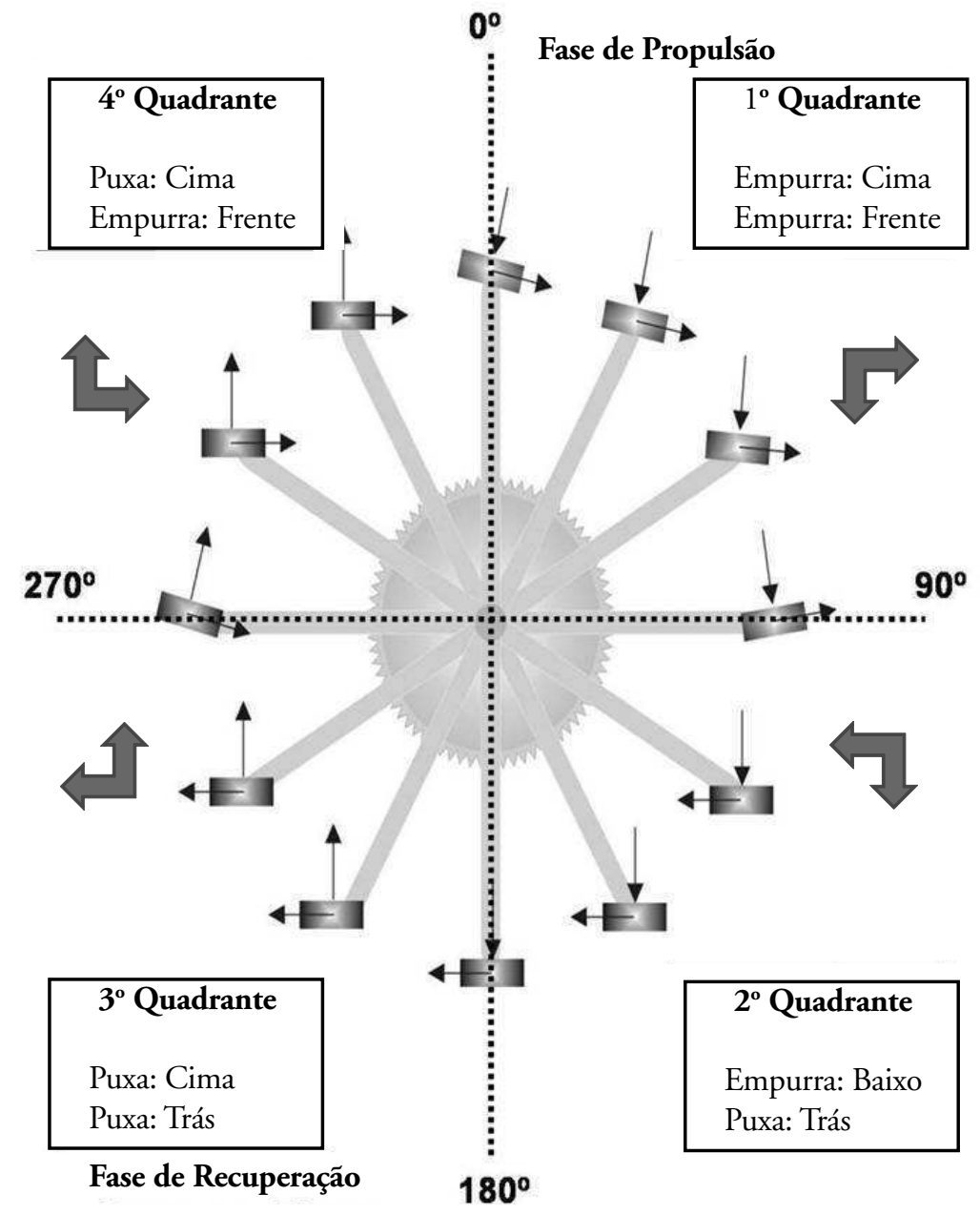

FIGURA 3 -Planilha de orientação das forças ao longo do ciclo da pedalada apresentada ao indivíduo nos intervalos da série de pedalada durante a interação do avaliador com o avaliado.

O FVA e o FA foram apresentados aos indivíduos dos grupos experimental e controle, respectivamente, ao final da aquisição do sinal de força, ou seja, no intervalo entre as séries de prática. A imagem gráfica apresentada aos indivíduos do grupo experimental foi a sua curva de força efetiva (FE). A curva do indivíduo foi sobreposta a uma curva de referência. A curva de referência utilizada como meta a ser atingida pelo indivíduo foi obtida de um ciclista de elite integrante da Federação Gaúcha de Ciclismo, 
avaliado previamente no Laboratório de Pesquisa do Exercício (LAPEX) da Escola de Educação Física
(ESEF) da Universidade Federal do Rio Grande do Sul (UFRGS) (FIGURA 4).

\section{Força Efetiva Referência}

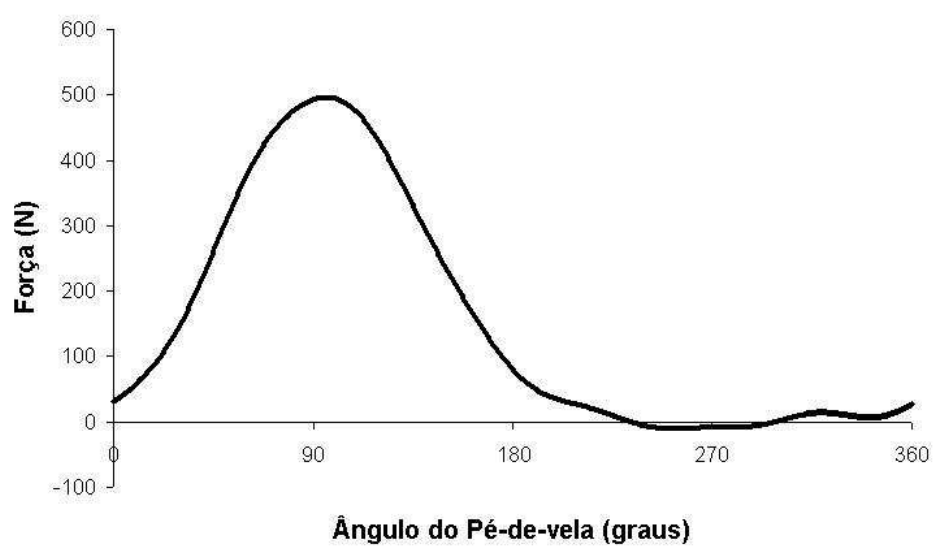

FIGURA 4 - Curva de FE utilizada como referência a ser alcançada no FVA.

A curva de FE do ciclista de elite serviu de referência apenas em termos de formato, ou seja, a orientação transmitida para os indivíduos era de que estes tentassem produzir uma curva de FE com um comportamento, ao longo do ciclo, semelhante à curva apresentada. Em nenhum momento foi requisitado aos participantes que tentassem atingir uma magnitude de aplicação de força semelhante à curva apresentada.

O período de sessóes de prática apresentou duração de sete dias e foi dividido em duas fases: FASE 1 ( $1^{\circ}$ ao $\left.5^{\circ} \mathrm{dia}\right)$ e FASE 2 (6o ao $\left.7^{\circ} \mathrm{dia}\right)$.

Cada sessão de prática apresentou duração de 35 minutos, sendo que os primeiros cinco minutos foram sem "feedback", pois serviram apenas para aquecimento e familiarização dos indivíduos com a bicicleta. No entanto, os indivíduos já estavam pedalando na cadência de $60 \mathrm{rpm}$.

Nos trinta minutos restantes, tanto os indivíduos do grupo experimental, quanto do grupo controle, receberam FVA e FA, respectivamente, de forma alternada, para não comprometer o aprendizado. O fornecimento do FVA e do FA em qualquer das fases das sessões de prática, foi sempre realizado com os indivíduos parados, sem pedalar.

Do $1^{\circ}$ ao $5^{\circ}$ dia das sessôes de prática, os indivíduos do grupo experimental e controle receberam FVA e FA por um minuto, respectivamente, para cada série de pedalada de um minuto, dessa forma, os indivíduos pedalavam um minuto e recebiam o "feedback" correspondente àquele minuto que foi pedalado. Esta estratégia fez com que os indivíduos recebessem um total de 75 minutos de "feedback" para 75 minutos de pedalada na primeira fase das sessões de prática (cinco sessões de 15 minutos de pedalada e 15 minutos de "feedback"). Entre uma série e outra de pedalada os indivíduos não estavam pedalando, apenas recebendo o "feedback" sobre a sua técnica de pedalada.

Do $6^{\circ}$ ao $7^{\circ}$ dia das sessões de prática, os indivíduos do grupo experimental e controle receberam FVA e FA por um minuto, respectivamente, para cada série de dois minutos das sessóes de prática, dessa forma, os indivíduos pedalavam dois minutos e recebiam o "feedback" correspondente aos dois minutos anteriormente pedalados, o que fez com que os indivíduos recebessem um total de 20 minutos de "feedback" para 40 minutos de pedalada na segunda fase das sessões de prática (duas sessões de 20 minutos de pedalada e 10 minutos de "feedback").

Ao final das sessões de prática, os indivíduos do grupo experimental e controle receberam $75 \mathrm{mi}$ nutos de FVA e FA, respectivamente, do $1^{\circ}$ ao $5^{\circ}$ dia (FASE 1) e 20 minutos do $6^{\circ}$ ao $7^{\circ}$ dia (FASE 2), totalizando 95 minutos de FVA para o grupo experimental e de FA para o grupo controle durante sete dias de sessões de prática.

Este estudo adotou uma redução maior do tempo de "feedback" em relação a estudos revisados. A redução da frequência de "feedback" da FASE 1 para a FASE 2 foi de aproximadamente $73 \%$. Este procedimento foi adotado com o intuito de não causar dependência ao aprendiz, pois de acordo com SANDERSON e CAVANAGH (1990), a integralidade da informação visual pode causar dependência ao aprendiz comprometendo o movimento aprendido quando o mesmo é realizado sem o fornecimento de "feedback". 
O armazenamento dos arquivos para a visualização gráfica da pedalada de cada sujeito do grupo experimental teve a duração de $30 \mathrm{~s}$, o que representa, aproximadamente, 30 ciclos consecutivos de pedalada. Na FASE 1, o registro foi realizado nos últimos 30 segundos da cada minuto da série de pedalada. Na FASE 2, o registro foi realizado nos últimos 30 segundos do segundo (último) minuto da séria de pedalada.

Após o registro das forças aplicadas ao pedal pelo indivíduo, os dados foram processados através de uma rotina de processamento de dados (elaboradas no "software" SAD 32) desenvolvida adequadamente para cada momento deste estudo, ou seja, para o período de pré-experimento, para as sessões de prática e para o período de pós-experimento. Dessa forma, a curva de FE foi obtida e apresentada no monitor do computador. Em seguida, a curva foi analisada pelo avaliador e apresentada ao indivíduo do grupo experimental sobreposta à curva de referência. Assim era possível, para o indivíduo, ver o quão próximo, ou distante, estava a sua curva de FE em relação a curva de $\mathrm{FE}$ referência. Em seguida à apresentação da curva de FE ao indivíduo, foi apresentada ao mesmo, a planilha de orientação e fornecidas as informaçōes sobre o direcionamento das forças no pedal. As informações sobre a curva de FE, bem como as informações sobre o direcionamento das forças no pedal, foram apresentadas ao indivíduo no intervalo das séries de pedalada, ou seja, dentro do tempo de um minuto.

O tempo de processamento das informaçóes depois de adquiridas (gravadas) foi de, aproximadamente, $2 \mathrm{~s}$. Dessa forma, a informação foi fornecida ao sujeito, aproximadamente, $2 \mathrm{~s}$ após a gravação, restando o tempo de, aproximadamente, $58 \mathrm{~s}$ para fornecer a apresentação da curva de FE e as informações para que os sujeitos pudessem melhorá-la.

Os indivíduos de ambos os grupos participaram das sessōes de prática de forma individual, estando na presença apenas do avaliador e do operador do equipamento, mas mantendo contato apenas com o avaliador. Para uma melhor organização das séries de prática, foi realizada uma escala de horários para cada indivíduo, sendo esta mantida ao longo de todo o processo, o que fazia com que os indivíduos praticassem sempre no mesmo horário. Este procedimento foi realizado com o intuito de minimizar qualquer interferência possível nos resultados adquiridos. A cada troca de indivíduos durante as sessões de prática, foram realizados os devidos ajustes na bicicleta, ou seja, os ajustes na altura do selim, bem como a troca de sapatilhas, quando necessário.
Transcorridas 24 horas após o encerramento das sessões de prática, os sujeitos foram submetidos à avaliação no período de pós-experimento.

\section{Período de pós-experimento}

O período de pós-experimento foi composto de duas avaliaçôes: 1) pós; e 2) retenção. Para tanto foram utilizados os mesmos equipamentos e critérios estabelecidos no período de pré-experimento. O momento pós foi realizado 24 horas após o encerramento das sessóes de prática e o retenção foi realizado uma semana após a realização do momento pós. $\mathrm{O}$ momento retenção foi adotado para verificar se houve aprendizagem por parte dos indivíduos, ou seja, se ocorreu modificação no padrão de aplicação de força no pedal entre o momento pós e o momento retenção com a ausência das sessões de prática.

\section{Processamento dos dados}

A análise dos sinais de dinamometria e eletrogoniometria foi realizada utilizando-se rotinas de processamento implementadas para o "software" SAD. Os dados dos indivíduos foram submetidos a uma comparação entre os três momentos (pré, pósteste e teste de retenção) e grupos (experimental e controle). Realizou-se a análise dos dados a partir da realização da média dos 10 primeiros ciclos alternados de pedalada.

A partir da decomposição das forças normal (Fy) e tangencial ( $\mathrm{Fx})$ em relação ao pé-de-vela, foi possível a realização do cálculo da força efetiva (FE) (Equação 1) que consiste na soma das componentes de força normal ( $\mathrm{Fy}$ ) e tangencial ( $\mathrm{Fx}$ ) perpendiculares ao pé-de-vela, utilizando o ângulo do pedal relativo ao pé-de-vela (FIGURA 5) (Hug et al., 2003).

$$
F E=F y^{\perp}+F x^{\perp}
$$



FIGURA 5 - $(\alpha)$ ângulo do pedal relativo ao pé-de-vela e ( $\beta)$ ângulo do pé-de-vela. 
A força resultante aplicada ao pedal também foi calculada a partir da decomposição das forças normal (Fy) e tangencial (Fx) (Equação 2). O pedal instrumentado utilizado neste estudo não permite a mensuração da componente de força médio-lateral, logo, esta força resultante aplicada ao pedal representa a força total aplicada no plano sagital.

$$
F R=\sqrt{F y^{2}+F x^{2}} \text { (2) }
$$

Posteriormente foram calculados os impulsos das forças efetiva (IFE) e resultante (IFR) (Equações $3 \mathrm{e}$ 4 respectivamente; LAFORTUNE \& CAVANAGH, 1983).

$$
\begin{aligned}
& I F E=\int_{0}^{x} d t F E \\
& I F R=\int_{0}^{x} d t F R
\end{aligned}
$$

A técnica de pedalada do indivíduo ao longo do ciclo foi analisada através do índice de efetividade (IE). Este consiste na razão entre o impulso da força efetiva (IFE) e o impulso da força resultante IFR (Equação 5). O IE indica o quanto da FR foi direcionada como FE, ou seja, utilizada para a propulsão da bicicleta (LAFORTUNE \& CaVAnagh, 1983; Sanderson, 1991).

$$
I E=\int_{0}^{x} d t F E / \int_{0}^{x} d t F R
$$

Foi utilizado também para análise da técnica da pedalada, a taxa de efetividade (TE), que consiste na razão entre as forças efetiva (FE) e resultante (FR) ao longo do ciclo (Equação 6).

$$
T E=F E / F R
$$

Neste estudo foi analisado o índice e a taxa de efetividade de cada indivíduo antes e depois das sessões de prática. Enquanto que o IE representa um valor númerico sobre a técnica da pedalada, a TE expressa a técnica da pedalada de forma gráfica. Logo, entende-se que, para uma melhor visualização e compreensão dos reultados, a análise destas duas variáveis são fundamentais.

\section{Tratamento estatístico dos dados}

Foi realizada a análise descritiva dos dados, com o cálculo das médias e dos desvios-padrão. A normalidade, a homogeneidade e a esfericidade dos dados foram verificados com a utilização dos testes de Shapiro-Wilk, Levene e Mauchly, respectivamente.

Para a comparação intra-grupos das médias de IE ao longo do ciclo da pedalada, utilizou-se análise de variância para medidas repetidas e um teste "posthoc" de Bonferroni para verificar as diferenças entre os momentos (efeitos das sessôes de prática).

Já para a comparação inter-grupos das médias de IE ao longo do ciclo da pedalada, aplicou-se um teste $\mathrm{T}$ de Student para dados independentes. Utilizouse o "software" SPSS (versão 12.0) e adotou-se $\alpha=$ 0,05 como nível de significância.

\section{Resultados}

\section{Índice de efetividade ao longo do ciclo da pedalada}

A TABELA 1 apresenta os resultados de índice de efetividade dos grupos experimental e controle. As comparações apresentadas são entre os momentos pré, pós e retenção em cada grupo.

A comparação das médias de IE do grupo experimental mostrou diferença significativa ( $\mathrm{F}(2$, 16) $\left.=57,043 ; \mathrm{p}<0,001 ; \eta^{2}=0,877\right)$ entre os três momentos estudados (pré, pós e retenção). Este resultado mostra que aproximadamente $87,7 \%$ da variância do IE podem ser explicados pelo aprendizado.

As diferenças significativas encontradas entre os momentos no grupo experimental foram entre pré e pós $(\mathrm{p}=0,001)$, pré e retenção $(\mathrm{p}<0,001)$ e pós e retenção $(\mathrm{p}=0,006)$.

No grupo controle a comparação das médias de IE nos três momentos indicou diferença significativa $\left(\mathrm{F}(2,16)=25,166 ; \mathrm{p}<0,001 ; \eta^{2}=0,759\right)$. Este resultado mostra que, aproximadamente, $75,9 \%$ da variância no IE podem ser explicados pelo aprendizado e pelo FA.

As diferenças significativas entre os momentos, no grupo controle, foram entre pré e pós $(\mathrm{p}=0,001)$ e pré e retenção $(p<0,001)$. Não foi observada diferença significativa na média de IE entre os momentos pós e retenção $(p=0,427)$. As comparações dos valores de IE inter-grupos nos três momentos de avaliação podem ser visualizadas na FIGURA 6. 
TABELA 1 - IE (\%) dos grupos experimental e controle nos três momentos.

\begin{tabular}{ccccc}
\hline Grupo & N & Pré & Pós & Retenção \\
\hline Exp & 10 & $26,9 \pm 4,43^{\mathrm{a}, \mathrm{b}}$ & $53 \pm 12,87^{\mathrm{a}, \mathrm{c}}$ & $65,9 \pm 6,31^{\mathrm{b}, \mathrm{c}}$ \\
Cont & 9 & $27 \pm 2,95^{\mathrm{a}, \mathrm{b}}$ & $46,77 \pm 9,58^{\mathrm{a}}$ & $44,33 \pm 8,06^{\mathrm{b}}$ \\
\hline
\end{tabular}

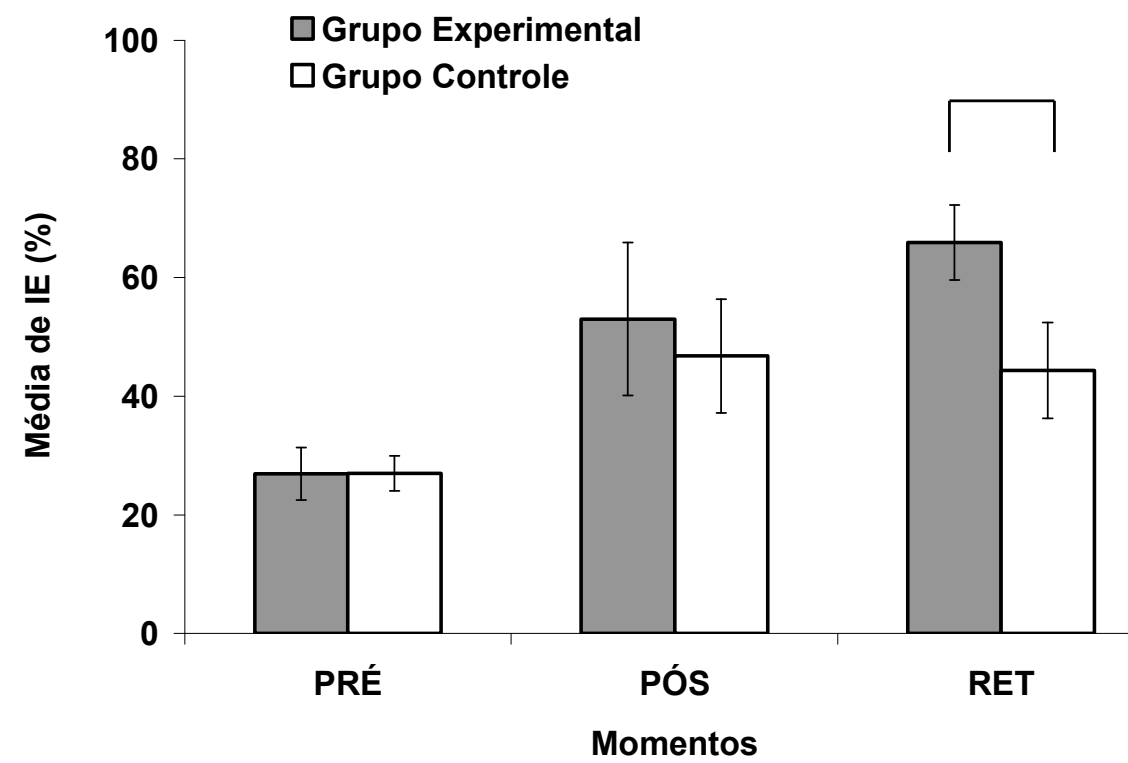

$O$ colchete ( П ) indica diferença significativa inter-grupos.

FIGURA 6 - Comparação das médias de IE entre os grupos experimental e controle nos três momentos.

Na comparação das médias de IE do grupo experimental com o grupo controle no momento pré não houve diferença significativa $(T(17)=1,644 ; p=0,955)$.

Embora o grupo experimental tenha apresentado um valor médio de IE maior do que o grupo controle no momento pós, não houve diferença entre o IE dos dois grupos $(T(17)=0,392 ; p=0,253)$.

A comparação das médias de IE dos grupos experimental e controle, no momento retenção, indicou diferença significativa $(T(17)=0,899 ; \mathrm{p}<0,001)$, com maiores valores para o grupo experimental.

\section{Taxa de efetividade ao longo do ciclo da pedalada}

A FIGURA 7 mostra as curvas médias da TE do grupo experimental ao longo do ciclo da pedalada nos três momentos de avaliação, note-se que as avaliações e comparações da TE são de cunho qualitativo.

Entre os momentos pré e pós, no grupo experimental, foi observado um melhor aproveitamento na técnica da pedalada ao longo dos quatro quadrantes do ciclo, sendo as melhoras mais expressivas no segundo e terceiro quadrantes. Já entre os momentos pré e retenção foi observado melhor aproveitamento na técnica da pedalada ao longo do segundo e terceiro quadrantes, mas a diferença mais relevante ocorreu no quarto quadrante do ciclo. Já entre os momentos pós e retenção, observouse melhor aproveitamento na técnica de pedalada no primeiro e quarto quadrantes, sendo que as mais expressivas ocorreram no quarto quadrante do ciclo.

A FIGURA 8 mostra as curvas médias da TE do grupo controle ao longo do ciclo da pedalada nos três momentos de avaliação. Observe novamente que as avaliações e comparaçōes da TE são de cunho qualitativo.

Entre os momentos pré e pós do grupo controle, observaram-se modificações na TE ao longo dos quatro quadrantes, sendo as mais expressivas no segundo e terceiro quadrantes. Entre os momentos pré e retenção não foram observadas modificações relevantes no comportamento da curva ao longo do ciclo, apenas pequenas modificações no segundo e terceiro quadrantes do ciclo. Já entre os momentos pós e retenção, foram observadas modificaçōes na TE ao longo dos quatro quadrantes, obtendo, o grupo controle, um melhor aproveitamento na TE, no segundo e terceiro quadrantes do ciclo no momento pós.

A FIGURA 9 mostra as curvas médias da TE dos grupos experimental e controle ao longo do ciclo da pedalada. É possível visualizar a similaridade da técnica de ambos os grupos no momento pré. 




Ângulo do pé-de-vela (graus)

FIGURA 7 - Taxa de efetividade do grupo experimental ao longo do ciclo da pedalada durante os três momentos de avaliação (pré, pós e retenção).

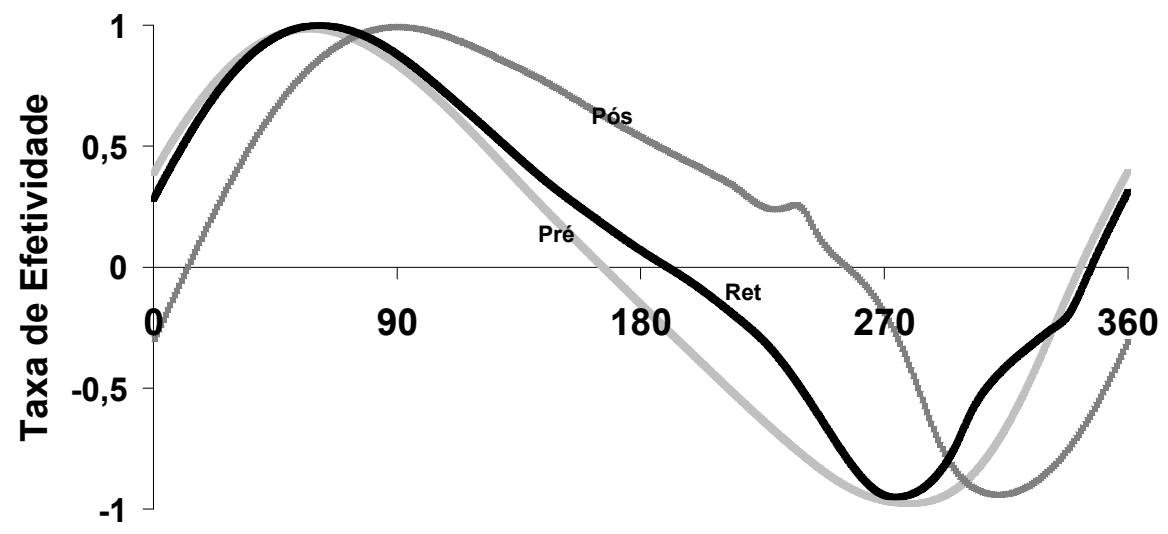

Ângulo do pé-de-vela (graus)

FIGURA 8 - Taxa de efetividade do grupo controle ao longo do ciclo da pedalada durante os três momentos de avaliação (pré, pós e retenção).

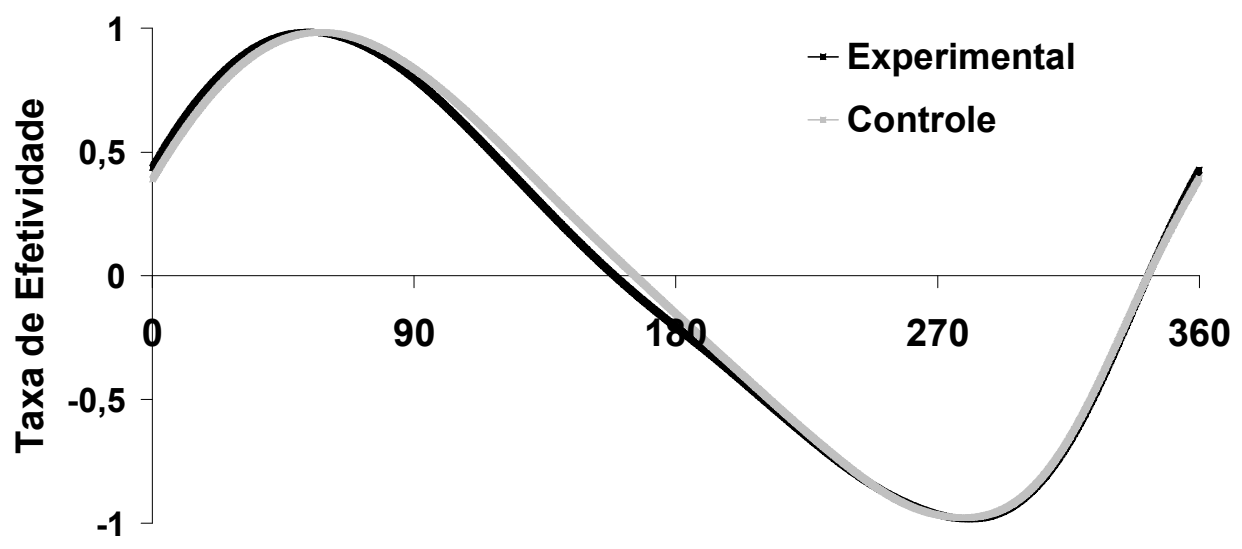

Ângulo do pé-de-vela (graus)

FIGURA 9 - Taxa de efetividade média dos grupos experimental e controle sobrepostos no momento pré ao longo do ciclo da pedalada. 
A FIGURA 10 mostra as curvas médias da TE dos grupos experimental e controle ao longo do ciclo da pedalada no momento pós. Há uma similaridade técnica de ambos os grupos após as sessōes de prática.

Já a FIGURA 11 mostra as curvas médias da TE dos grupos experimental e controle ao longo do ciclo da pedalada no momento retenção. Foi possível visualizar um melhor aproveitamento na técnica da pedalada do grupo experimental quando comparado ao grupo controle no momento retenção, principalmente no segundo, terceiro e quarto quadrantes do ciclo.

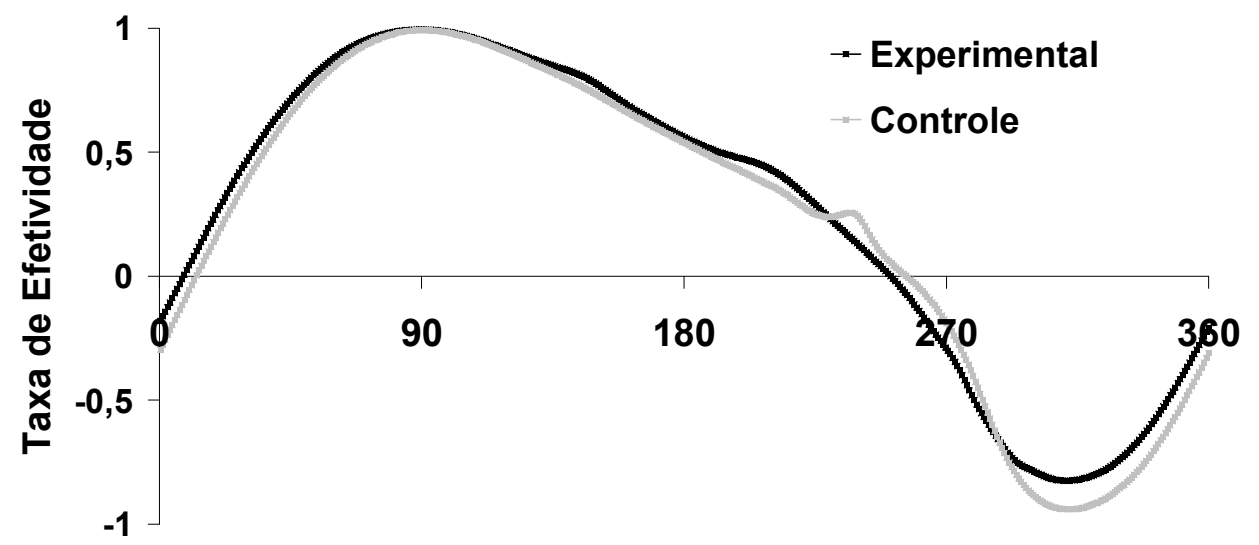

Ângulo do pé-de-vela (graus)

FIGURA 10 - Taxa de efetividade média dos grupos experimental e controle sobrepostos no momento pós ao longo do ciclo da pedalada.

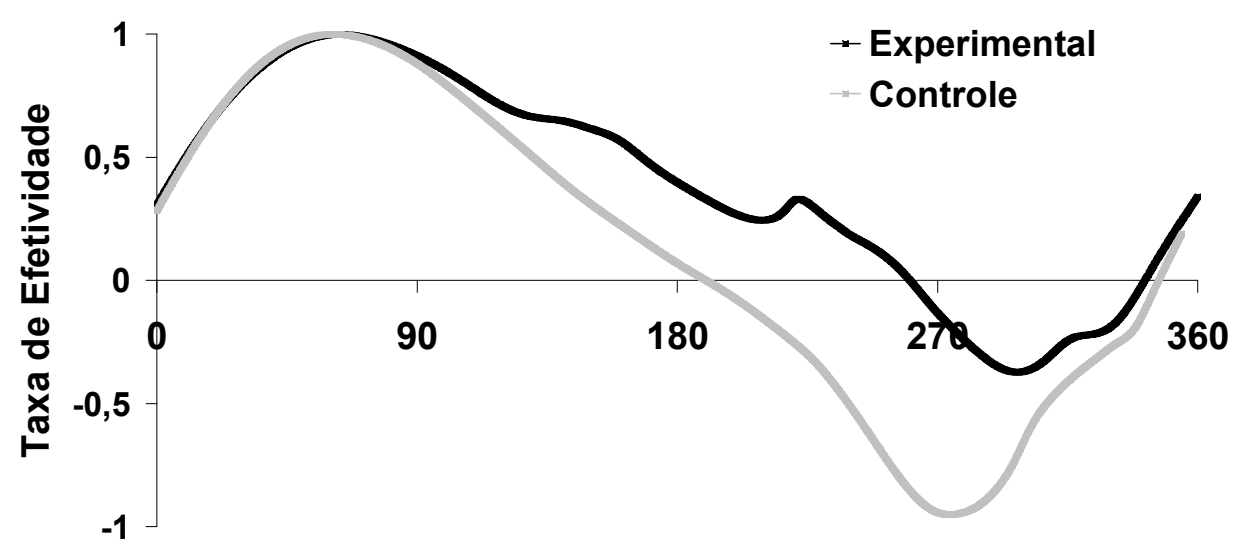

Ângulo do pé-de-vela (graus)

FIGURA 11 - Taxa de efetividade média dos grupos experimental e controle sobrepostos no momento retenção ao longo do ciclo da pedalada.

\section{Discussão}

O IE é uma variável que depende da FE. Já a FE depende da magnitude e da orientação das componentes de força normal (Fy) e tangencial ( $\mathrm{Fx}$ ) aplicadas no pedal, uma vez que é considerada a força transmitida para o pé-de-vela, gerando torque propulsor. Sendo assim, pode-se inferir que o IE é a variável que melhor expressa a técnica da pedalada (LAFORTUNE \& CAVANAGH, 1983).
Ao final das sessões de prática, pode-se observar, que os resultados encontrados no momento pós (TABELA 1) corroboram com a literatura no que diz respeito à melhora do IE com a prática da pedalada. No entanto, representam mais do que o triplo da diferença encontrada por HENKE (1998), que observou um aumento de $8 \%$ na média de IE entre o período de pré 
e pós-experimento. Entretanto, HENKE (1998) realizou um protocolo de apenas uma sessão de 30 minutos com FVA e não utilizou um teste de retenção para avaliar a aprendizagem da técnica da pedalada por parte dos indivíduos. Portanto, a comparação entre o estudo de HeNkE (1998) com o presente estudo, refere-se apenas à diferença encontrada entre os momentos pré e pós.

O resultado esperado em relação ao teste de retenção do grupo experimental era que se mantivesse igual ao momento pós, ou que, pelo menos, não fosse significativamente menor, para que se pudesse confirmar a hipótese da aprendizagem da técnica da pedalada. Entretanto, observou-se um aumento significativo na média de IE do momento pós para o momento retenção de aproximadamente 12,9\% (TABELA 1).

Este aumento pode estar relacionado com a memória visual armazenada durante as sessóes de prática e com "feedback" intrínseco. $\mathrm{Na}$ tentativa de manter o mesmo padrão de aplicação de força no pedal, obtido no momento pós, que foi realizado no dia seguinte à última sessão de prática, e, portanto, com memória visual recente, os indivíduos buscaram na memória não só a imagem (neste caso o FVA), mas também, os recursos adotados por eles como forma de aprendizado intrínseco (SINGER, 1975). Estes dois fatores somados podem ter causado uma "otimização" das informações fornecidas para a execução da técnica da pedalada, uma vez que o indivíduo tenha utilizado outras fontes proprioceptivas de informação, e estas, por sua vez, tenham contribuído de forma positiva para a realização do movimento.

$\mathrm{O}$ armazenamento de informações proprioceptivas pode estar relacionado com a redução do FVA ao longo das sessóes de prática, pois, à medida que a informação visual era reduzida, era necessário adquirir outras fontes de informação para auxiliar na realização do movimento e compensar as informações retiradas quando o FVA fora removido (TANI, Freudenheim, Meira Junior \& Corrêa, 2004).

Segundo Sanderson e Cavanagh (1990), o ensino na técnica da pedalada não se trata de um processo de aprendizagem, mas de reaprendizagem, visto que o indivíduo já aprendeu, durante a infância, a andar de bicicleta. Porém, o enfoque adotado na infância era apenas o equilíbrio, e não o direcionamento das forças aplicadas ao pedal da bicicleta. Dessa forma, é necessário que o indivíduo armazene novas informações na memória para execução da uma nova habilidade, ampliando, assim, seu repertório motor, o que pode contribuir na criação de novas estratégias de aplicação de força.

Outro fator de destaque é que o aumento da média do IE no teste de retenção mostra, também, que a redução do FVA, ao longo das sessões de prática, não causou nenhuma dependência aos indivíduos do grupo experimental. Este fato está de acordo com estudos relacionados com o ensino do ciclismo, nos quais também não se observou dependência por parte dos indivíduos com a redução do FVA (BROKER, GREGOR $\&$ SCHMidT, 1993; SANDERSON \& CAVANAGH, 1990).

O aumento da média do IE do grupo controle do momento pré para o pós foi de, aproximadamente, $19 \%$. Esta diferença está de acordo com a literatura no que diz respeito ao percentual de aumento do momento pré para o pós, já que HENKE (1998) obteve um aumento de $8 \%$ na média do IE ao longo do ciclo da pedalada entre os mesmos momentos.

Porém, com relação à média do IE no momento pós, HENKE (1998) encontrou uma média de 59\% ao longo do ciclo da pedalada, enquanto que o grupo controle obteve uma média, aproximadamente, $12 \%$ menor.

$\mathrm{O}$ aumento do IE, observado entre os momentos pré e pós, pode ser atribuído ao uso do FA. Já entre os momentos pós e retenção, houve uma diminuição na média de IE, porém, sem diferença significativa, o que mostra que os indivíduos do grupo controle mantiveram a similaridade no nível de desempenho, mesmo com um intervalo de uma semana sem pedalar e sem FA. De acordo com Rose (1997), Magill (2000) e Schmidt e Wrisberg (2001), a aprendizagem é observada a partir de níveis estáveis no desempenho da técnica de um movimento; portanto, este fato também caracteriza a aprendizagem.

Os resultados do grupo controle contradizem os resultados de SAnderson e CAVANagh (1990), que utilizaram FVA para a modificação mecânica do padrão da pedalada. No estudo de SANDERSON e CAVANAGH (1990), o grupo controle manteve níveis estáveis no desempenho da técnica da pedalada tanto no pós-teste 1 , quanto no pós-teste 2 (retenção) em relação ao pré-teste. Dessa forma, pode-se afirmar que, no presente estudo, mesmo com valor significativamente menor na média do IE em relação ao FVA, o FA também proporcionou aprendizagem.

$\mathrm{O}$ fato de o grupo experimental ter obtido, no momento retenção, um valor maior de IE em relação ao grupo controle (aproximadamente $21 \%$ ), significa que os indivíduos que receberam o FVA conseguiram transferir para o pé-de-vela uma maior percentual da força total aplicada no pedal.

Embora a literatura apresente estudos nesta linha de investigação, com algumas diferenças de desenho experimental, procedimentos metodológicos e procedimentos de análise, pode-se afirmar que os resultados de IE do presente estudo estão de acordo com os achados 
na literatura. No que diz respeito ao efeito da aprendizagem mediante o uso de FVA, estudos que também avaliaram a retenção dos indivíduos em sete dias observaram níveis estáveis no desempenho da técnica da pedalada, não havendo redução no desempenho da técnica da pedalada durante execução do movimento (BRoker, GREgOR \& SCHMidT, 1993; SANDERSON \& Cavanagh, 1990), o que, para Singer (1975), Rose (1997), Magill $(1984,1997,2000)$ e Schmidt e WRISBERG (2001), caracteriza a aprendizagem.

Este fato está, possivelmente, associado à apresentação do FVA. De acordo com HeNKE (1998), a informação visual possibilita uma aprendizagem mais rápida da técnica da pedalada, pois permite uma comparação entre o aprendizado intrínseco e o extrínseco, ou seja, entre o que os indivíduos estão sentindo durante o movimento da pedalada e o que os mesmos realmente produziram e visualizaram ao final do movimento.

Com relação às médias do IE, é possível estabelecer algumas comparaçóes com estudos realizados com objetivos diferentes do presente estudo, mas que também avaliaram ciclistas recreacionais e calcularam o IE ao longo da pedalada.

No estudo realizado por ERICSON e NISSEL (1988), que avaliou a diferença das forças aplicadas no pedal com a utilização de pedais de ciclismo e pedaleiras em seis sujeitos do sexo masculino, sob diferentes cadências, cargas e alturas de selim, encontraram-se médias de IE de 44\% ( \pm 1\%) na cadência de $60 \mathrm{rpm}$. Este resultado de ERICSON e NisSEL (1988) assemelhase ao do grupo controle do presente estudo, o que reflete que, mesmo o grupo controle sendo submetido a sessões de prática recebendo FA, manteve sua média semelhante a indivíduos avaliados na mesma cadência e sem serem submetidos a qualquer tipo de sessão de prática com "feedback". No entanto, para ERICSON e Nissel (1988), o IE consiste da razão entre a FE e a FR, o que, neste estudo, é considerado como taxa de efetividade (TE) e apresentado através de uma curva. Já o IE, no presente estudo, consiste na razão entre o impulso linear da FE e o impulso linear da FR.

DAVIS e Hull (1981), diferentemente de ERICSON e NISSEL (1988), utilizam a potência para o cálculo do IE. Em uma situação em que os indivíduos pedalaram na cadência de $80 \mathrm{rpm}$, apresentou-se uma média de IE de 26,6\%, o que é inferior à média do grupo controle do presente estudo (44,33\%). Este resultado (aumento de IE no grupo controle) contradiz os achados de ERICSON e Nissel (1988), indicando, de alguma forma, que possa ter ocorrido aprendizagem também no grupo controle, pois este, após receber FA, apresentou valores médios de IE maiores do que os indivíduos que foram simplesmente avaliados e não receberam nenhum tipo de "feedback".

No estudo realizado por LAFORTUNE e CAVANAGH (1983), que avaliou a efetividade da pedalada de ciclistas recreacionais e calculou o IE utilizando a razão entre o impulso linear da FE e o impulso linear da FR, que corresponde ao cálculo do presente estudo, foi encontrado um valor médio de IE de 48,1\%. Este valor é similar à média do grupo controle, o que, novamente, remete à suposição de que o FA não foi tão eficaz para o ensino da técnica da pedalada quando comparado ao FVA.

Os resultados do estudo realizado por LAFORTUNE e CAVANAGH (1983), apresentam uma média de IE aproximadamente $17 \%$ menor em relação à média do grupo experimental do presente estudo no momento retenção. Este dado mostra que a diferença do grupo experimental (que recebeu FVA), com o grupo controle (que recebeu FA) e com grupos que não receberam nenhum tipo de "feedback", é praticamente a mesma, confirmando a eficiência do FVA no ensino da técnica da pedalada no ciclismo.

Resultados similares de IE foram encontrados por HENKE (1998), que utilizou um sistema de FVA em tempo real para avaliar ciclistas competidores profissionais e encontrou média de IE, ao final de um único teste, de $60 \%$, que se assemelha à média de IE obtida pelo grupo experimental. Os sujeitos do estudo de Henke (1998), pedalaram em uma cadência de $60 \mathrm{rpm}$ com carga de $200 \mathrm{~W}$.

Coyle, Feltner, Kautz, Hamilton, Montain, Baylor, Abraham e Petrer (1991) avaliaram as características fisiológicas e biomecânicas de 15 ciclistas de elite pertencentes USCF (Federação de Ciclismo dos Estados Unidos) divididos em duas categorias: categoria 1 - ciclistas com a média de tempo abaixo de 56 minutos para $40 \mathrm{~km}$ contra-relógio; e categoria 2 - ciclistas com a média de tempo acima de 56 minutos para $40 \mathrm{~km}$ contra-relógio. Com relação aos achados biomecânicos deste estudo, foram encontradas médias de IE de $63,5 \%( \pm 4,7 \%)$ para a categoria 1 e $69,3 \%( \pm 3,2 \%)$ para a categoria 2 .

Ao comparar os resultados encontrados por CoYLE et al. (1991) com os do presente estudo, foram verificadas médias similares de IE do grupo experimental quando comparado às categoria 1 e 2 . Esta comparação também foi realizada apenas de forma ilustrativa com o intuito de mostrar que o aumento na média do IE do grupo experimental foi relevante.

SANDERSON e BLACK (2003) avaliaram o efeito do ciclismo prolongado nas forças aplicadas ao pedal, em 12 ciclistas homens pertencentes à CCA (Canadian Cycling Association). Os ciclistas pertenciam a 
modalidades distintas, sendo sete ciclistas de estrada de categoria 1, 2 ou 3 e cinco ciclistas de "mountain bike" de categoria "Sport", "Expert" ou Elite. Estes pesquisadores, ao final do experimento, encontraram uma média de IE de 63\% ( $\pm 9 \%)$, similar à média do grupo experimental no momento retenção.

Isto mostra que a média de IE alcançada pelo grupo experimental, com a realização das sessões de prática utilizando o FVA, apresenta valores condizentes com as médias de IE encontradas na literatura. Isso sugere que este grupo aprendeu a técnica da pedalada, embora utilizando uma carga de trabalho muito inferior à utilizada por ciclistas de elite.

O grupo controle, por sua vez, apresentou uma diminuição no IE no momento retenção para 44,33\% $( \pm 8,06 \%)$. Mas, uma vez que esta diferença não foi significativa em relação ao momento pós, é possível afirmar que houve aprendizagem também no grupo controle mediante o uso do FA; porém, com uma média de IE inferior à do grupo experimental (cerca de 21\%).

Entretanto, ao comparar o grupo controle com outros estudos, observa-se uma grande diferença no que diz respeito à técnica da pedalada, pois a média de IE do grupo controle, quando comparada à média de IE do estudo realizado por HENKE (1998), apresenta valores, aproximadamente, $15 \%$ menores. Este mesmo grupo, quando comparado com as categorias 1 e 2 do estudo de CoYle et al. (1991), apresentou valores médios menores (respectivamente 19\% e 24\%) de IE.

Estes resultados mostram que a média de IE do grupo controle, após a realização das sessões de prática com FA, está bem abaixo das médias de ciclistas de elite encontradas na literatura, o que sugere uma certa deficiência na técnica da pedalada. Além disso, a diferença de aproximadamente $21 \%$ nas médias de IE encontrada entre o grupo experimental e o grupo controle é semelhante à diferença encontrada entre a literatura e o grupo controle.

Estes resultados mostram que, embora o grupo controle tenha mostrado valores estáveis no desempenho, o que caracteriza a aprendizagem da técnica da pedalada, ainda apresenta um padrão técnico não condizente ao de ciclistas de elite. Já o grupo experimental apresenta um padrão técnico coerente ao de ciclistas, embora exista uma grande diferença na carga de trabalho utilizada.

Os achados do presente estudo mostram que mesmo o FA proporcionando aprendizagem para o grupo controle, o FVA apresenta um efeito muito superior na aprendizagem, considerando-se os resultados obtidos por meio da análise do IE. Além disso, esta variável é a que tem sido utilizada para o estudo da aprendizagem motora, por ser a que melhor expressa a técnica da pedalada.

Uma outra maneira de se visualizar a efetividade da pedalada é por meio da taxa de efetividade (TE). A FIGURA 7 mostrou a TE do grupo experimental nos três momentos avaliados. A partir de uma análise qualitativa, pode-se visualizar, na comparação entre os momentos pré e pós, uma melhora na técnica da pedalada ao longo dos quatro quadrantes do ciclo, sobretudo no segundo e terceiro quadrantes. Este resultado pode ser atribuído, principalmente, a uma melhor orientação empregada na força aplicada ao pedal, ou seja, os indivíduos do grupo experimental, conseguiram melhorar o direcionamento da componente tangencial da força $(\mathrm{Fx})$.

$\mathrm{Na}$ comparação entre os momentos pré e retenção, pode-se observar na FIGURA 7, que o grupo experimental conseguiu aprimorar ainda mais o direcionamento da componente Fx. Esta melhora apareceu no segundo, terceiro e, principalmente, no quarto quadrante do ciclo. Já entre os momentos pós e retenção, observou-se, também, um melhor aproveitamento das forças aplicadas ao pedal, porém no primeiro e quarto quadrantes do ciclo.

Ao final das sessões de prática e, após a realização do momento pós, pode-se observar, por meio do momento retenção, que o grupo experimental conseguiu melhorar consideravelmente sua técnica de pedalada. Este resultado pode ser atribuído ao efeito do FVA, que proporcionou a este grupo, pelo comportamento apresentado nas curvas de TE (FIGURA 7), não só um aumento da magnitude, mas, principalmente, um melhor direcionamento das forças aplicadas ao pedal. Este fato culminou na aproximação da curva de TE do valor 1 no primeiro e segundo quadrantes, que significa uma maior aplicação de força total propulsora, e distanciou a curva de TE do valor -1 no terceiro e quarto quadrantes, que significa uma redução na aplicação de força total retrógrada.

A FIGURA 8 mostra a TE do grupo controle nos três momentos avaliados. A análise qualitativa, na comparação entre os momentos pré e pós, revelou algumas modificaçôes na TE ao longo dos quatro quadrantes do ciclo, sendo as mais expressivas durante o segundo e terceiro quadrantes. Este resultado pode estar relacionado a um melhor direcionamento da componente Fx.

Na comparação entre os momentos pré e retenção, observou-se, apenas, pequenas modificações durante o terceiro e quarto quadrantes, porém, sem muita relevância. A curva de TE no momento retenção apresentou um comportamento muito semelhante ao momento pré. Na comparação entre os momentos 
pós e retenção, observou-se em melhor aproveitamento na TE durante o terceiro e quarto quadrantes.

Após a realização das sessões de prática, pode-se observar, no momento retenção, que o grupo controle não conseguiu manter o mesmo aproveitamento na TE apresentado no momento pós. Além disso, este grupo, no momento retenção, apresentou um comportamento na TE semelhante ao momento pré, o que significa que houve uma redução no aproveitamento adquirido com as sessões de prática. Este fato mostra que o grupo controle sofreu certa dependência do FA, comprometendo o desempenho adquirido, quando este "feedback" foi removido.

O momento pré dos grupos experimental e controle, quando comparados (FIGURA 9), mostraram um comportamento semelhante na TE, o que remete ao fato de que ambos os grupos apresentavam uma similar efetividade na pedalada, antes dos mesmos serem submetidos às sessões de prática. No momento pós (FIGURA 10), este comportamento não se alterou, ou seja, ambos os grupos ainda apresentaram um comportamento semelhante ao final das sessões de prática. No entanto, no momento retenção (FIGURA 11), o grupo experimental apresentou um desempenho superior ao grupo controle, o qual confirma os resultados obtidos no IE. Estes resultados podem ser explicados da mesma forma que os resultados obtidos na análise do IE, que foram atribuídos ao uso do FVA, que permitiu um maior aprendizado intrínseco e não causou dependência com a sua remoção.

Após a realização do presente estudo foi possível observar que o conjunto de variáveis biomecânicas, utilizadas para compor o FVA, mostraram-se efetivas no ensino da técnica da pedalada do ciclismo. A utilização das variáveis biomecânicas presentes na pedalada serviram tanto na composição da representação visual da curva de FE quanto no desenvolvimento da planilha de orientação das componentes de força normal e tangencial. Além disso, estas variáveis permitiram, também, uma análise precisa da técnica da pedalada após a prática com o uso do FVA e FA. Sendo assim, a partir dos resultados encontrados, pode-se concluir que a proposta metodológica desenvolvida para ensinar a técnica da pedalada do ciclismo a partir do uso de FVA, bem como os procedimentos adotados para o controle das variáveis, foram adequados. Sugere-se a continuidade do presente estudo, para o crescimento do ciclismo no Brasil, abordando ainda questôes relacionadas ao processo de ensino-aprendizagem desta modalidade com a utilização de um sistema de captação de força bilateral (dois pedais instrumentados com plataforma de força) e com possibilidade de registro da componente de força médio-lateral.

\begin{abstract}
Interaction of biomechanical variables in the composition of visual augmented feedback for learning cycling

The aim of this study was to test a methodology to teach the pedaling technique of cycling using biomechanics variables to develop an augmented visual feedback system (AVF). Nineteen subjects divided in two groups (experimental $=10$ and control $=9$ ) without experience in cycling were used. A pre-test was conducted to determine the maximal oxygen uptake $\left(\mathrm{VO}_{2 \max }\right)$, and to establishe the work load to be used during the learning sessions which was defined to be the load that was associated with the $60 \%$ of $\mathrm{VO}_{2 \text { max }}$. Seven practice sessions were held. The experimental group was submitted to AVF and the control group to augmented feedback (AF). After the practice sessions, the retention test showed a significant increase in the index of effectiveness (IE) for the experimental group of $21 \%$ compared to the control group. These results showed that the biomechanics variables were appropriated to the development the AVF system and can contribute in the process pedaling technique learning.
\end{abstract}

UnITERMs: Cycling; Pedaling technique; Visual augmented feedback; Instrumented pedal. 


\section{Resumen}

Interacción de variables biomecánicas en la composición de feedback visual aumentado para el enseñanza del ciclismo

El objetivo de este estudio fue probar una metodología para enseñar la técnica de el ciclismo mediante la utilización de variables biomecánicas para desarrollar un sistema de feedback visual aumentado (FVA). Fue aplicado en 19 personas sin experiencia en el ciclismo, divididos en dos grupos (experimental $=10 \mathrm{y}$ control = 9). Inicialmente se realizó un pre-test para determinar el consumo máximo de oxígeno $\left(\mathrm{VO}_{2 \max }\right)$ y la carga de trabajo utilizada en las sesiones de práctica que correspondía al $60 \%$ del $\mathrm{VO}_{2 \max }$. El grupo experimental fue sometido a la FVA y el control a la feedback aumentado (FA). El ensayo de retención mostró un aumento del $21 \%$ en la media del índice de eficacia (IE) en el grupo experimental en comparación con el grupo control. Los resultados mostraron que las variables biomecánicas son apropiadas para el desarrollo de la FVA y puede contribuir al proceso de enseñanza y aprendizaje del ciclismo.

Palabras Clave: Bicicleta; Técnica de pedaleo; Las variables biomecánicas; Aprendizaje motor; Feedback visual aumentado.

\section{Referências}

ÁLVAREZ, G.; VINYOLAS, J.A. New bicycle oedal design for on-road meansurements of cycling forces. Journal of Applied Biomechanics, Champaign, v.12, p.131-41, 1996.

BROKER, J.P.; GREGOR, R.J.; SCHMIDT, R.A. Extrinsic feedback and the learning of kinetic patterns in cycling. Journal of Applied Biomechanics, Champaign, v.9, p.111-23, 1993.

BROOKE, J.D.; HOARE, J.; ROSENROT, P.; TRIGGS, R. Computerized system for measurement of force exerted withim each pedal revolution during cycling. Physiology and Behavior, New York, v.26, n.1, p.139-43, 1981.

CANDOTTI, C.T. Características fisiológicas e biomecânicas da pedalada de ciclistas e triatletas. 2003. Tese(Doutorado) - Universidade Federal do Rio Grande do Sul, Porto Alegre, 2003.

COYLE, E.F.; FELTNER, M.E.; KAUTZ, S.A.; HAMILTON, M.T.; MONTAIN, S.J.; BAYLOR, L.M.; ABRAHAM, L.D.; PETRER, G.W. Phisiological and biomechanical factors associated with elite endurance cycling performance. Medicine and Science in Sports Exercise, Hagerstown, v.23, p.93-107, 1991.

DAVIS, R.R.; HULL, M.L. Measurament of pedal loading in bicycling: II analysis and results. Journal of Biomechanics, New York, v.14, n.12, p.857-72, 1981.

DREYER NETO, C.; SCHMIDT, G.; CANDOTTI, C.T.; LOSS, J.F.; ZARO, M.A.; CERVIERI, A.; GUIMARĀES, A.C.S. Desenvolvimento de uma plataforma de força em pedal de ciclismo. Revista Brasileira de Biomecânica, São Paulo, v.3, p.39-44, 2001. ERICSON, M.O.; NISSEL, R. Efficiency of pedal forces during ergometer cycling. International Journal of Sports Medicine, Stuttgart, v.9, p.118-22, 1988.

GODOY, J.F. Biofeedback y deportes: potenciales lineas de actuación. Motricidad: European Journal of Human Movement, Cáceres, v.1, p.117-28, 1994.

HENKE, T. Real-time feedback of pedal forces for the optimization of pedaling technique in competitive cycling. In: INTERNATIONAL SYMPOSIUM ON BIOMECHANICS IN SPORTS, 16., 1998, Konstanz. Proceedings... Konstanz: University of Konstanz, 1998. p.174-77.

HOLDERBAUM, G.G.; GUIMARĀES, A.C.S.; PETERSEN, R.D.S. The use of augmented visual feedback on the learning of the recovering phase of pedaling. Brazilian Journal of Motor Behavior, Rio Claro, v.4, n.1, p.1-7, 2009.

HUG, F.; DECHERCHI, P.; MARQUESTE, T.; JAMMES, Y. EMG versus oxygen uptake cycling exercise in trained and untrained subjects. Journal of Electromyography and Kinesiology, New York, v.14, n.2, p.187-95, 2003.

HULL, M.L.; DAVIS, R.R. Measurament of pedal loading in bicycling: I instrumentation. Journal of Biomechanics, New York, v.14, n.12, p.843-56, 1981.

HULL, M.L.; WOOTTEN, D. An improved accuracy six-load component pedal dynamometer for cycling. Journal of Biomechanics, New York, v.29, n.8, p.1105-10, 1996.

LAFORTUNE, M.A.; CAVANAGH, P.R. Effectiveness and efficiency during bicycle riding. In: MATSUI, H.; KOBASHI, K. (Eds.). Biomechanics VIII-B. Champaign: Human Kinetics, 1983. p.928-36. 
MAGILL, R.A. Aprendizagem motora: conceitos e aplicações. São Paulo: Edgard Blucher, 1984. . São Paulo: Edgard Blucher, 2000.

Motor learning: concepts and applications. 5th ed. Boston: McGraw-Hill, 1997.

McARDLE, W.D.; KATCH, F.I.; KATCH, V.L. Fisiologia do exercício: energia, nutrição e desempenho humano. 3. ed. Rio de Janeiro: Guanabara Koogan, 1992.

ROSE, D.J. A multilevel approach to study of motor control and learning. Boston: Allyn \& Bacon, 1997.

SANDERSON, D.J. The influence of cadence and power output on the biomechanics of force application during steadystate cycling in competitive and recreational cyclists. Journal of Sports Sciences, London, v.9, p.191-203, 1991.

SANDERSON, D.J.; BLACK, A. The effect of prolonged cycling on pedal forces. Journal of Sports Sciences, London, v.21, p.191-99, 2003.

SANDERSON, D.J.; CAVANAGH, P.R. Use of augmented feedback for the modification of the pedaling mechanics of cyclists. Canadian Journal of Applied Sport Sciences, Champaign, v.15, n.1, p.38-42, 1990.

SCHMIDT, R.A.; WRISBERG, C.A. Aprendizagem e performance motora: uma abordagem da aprendizagem baseada no problema. 2. ed. Porto Alegre: Artmed, 2001.

SINGER, R.N. Motor learning and human performance: an application to physical education skills. 2nd ed. New York: Macmillan, 1975.

TANI, G.; FREUDENHEIM, A.N.; MEIRA JÚNIOR, C.M.; CORRÊA, U.C. Aprendizagem motora: tendências, perspectivas e aplicações. Revista Paulista de Educação Física, São Paulo, v.8, p.55-72, 2004.

WELBERGEN, E.; CLIJSEN, L.P.V.M. The influence of body position on maximal performance in cycling. European Journal of Applied Physiology, Berlin, v.61, p.138-42, 1990.

ENDEREÇO

Guilherme Garcia Holderbaum Laboratório de Pesquisa do Exercício, Porto Alegre Universidade Federal do Rio Grande do Sul - UFRGS Rua Felizardo, 750 90690-200 - Porto Alegre - RS -BRASIL e-mail: ghgarcia@ibest.com.br
Recebido para publicação: 19/11/2009

Revisado: 01/06/2012

Aceito: 14/06/2012 